\title{
4x4s Cars And The City: What Are The Limits Of Vehicle Manufacturer Responsibility?
}

\author{
Dr Peter Wells \\ Centre for Automotive Industry Research \\ Cardiff Business School \\ Colum Drive \\ Cardiff CF10 3EU
}

\section{Introduction}

Companies are social institutions, existing within dynamic situations in which cultural attitudes, norms, and expectations shift over time. That which used to be acceptable as a business practice might become unacceptable, or activities previously frowned upon may become legitimate. Importantly, this is not simply a matter reducible to the law per se, though changes in the legal framework are often a feature of such transitions.

This paper is about the consequences of the sale and use of large, four-wheel drive vehicles in urban areas. The main focus is on two issues: safety, and environmental concerns. The paper is derived from a document prepared for Greenpeace in relation to a campaign against so-called $4 \times 4$ vehicles in general, and Land Rover in particular. One starting point for this very 'live' social debate is perhaps that vehicle manufacturers, as custodians of engineering knowledge, have a responsibility to design and sell vehicles appropriate to the circumstances. Another is that if acting within the law, vehicle manufacturers simply offer their products to consumers and it is then up to those consumers to act responsibly.

Consumers are likely to put seek to maximise their personal utility first, and be rather less concerned about the wider social costs. In this respect, the purchase of a large or heavy vehicle might (or might not) be logical as a means of maximising personal safety, even if it also potentially reduces the safety of other road users. In broad terms, the prevailing free-market assumption is that consumers should be able to purchase and use whatever vehicle they wish from those available on the market, regardless of the wider social and environmental costs (negative externalities) because these are matters handled by the government and by companies. In the contemporary era it is widely accepted that companies have a 'corporate social responsibility' towards society and to the environment by virtue of the concentration of knowledge and resources the companies enjoy. The stance argued here is that this responsibility can and should involve more than mere compliance with regulatory controls and legal standards, but should also involve active leadership, enacting changes ahead of any such controls and standards, and using those resources to arrive at innovative solutions to social and environmental problems. 
In addition there is a rather more complex problem to do with targeting and the conduct of campaigns of this type. On the one hand, Land Rover as a single company has for many years been associated only with vehicles with an off-road capability. Other companies may have other specialisations: Aston Martin is known for sports cars for example. On the other hand, both of these two companies are in fact owned by a larger company, in this case Ford, with a very diverse product range and market coverage. Moreover, Ford includes within its own product range a great many $4 \times 4$ models, particularly for the US market.

\section{Defining the terms of debate}

The problem with any virulent debate of this type is that in practice it is often difficult to arrive at precise definition of the terms, even when in reality all parties to the discussion know what they are talking about.

There are various terms used somewhat inter-changeably to refer to the type of vehicles represented by the two Land Rover models in question: the Discovery and the Range Rover. These terms are not defined by legal requirements arising from vehicle test and registration legislation, but are used by the automotive industry and in popular discourse to describe the vehicles and to place them within so-called 'segments' of the overall market. The main terms in common usage are:

\section{$4 \times 4$ \\ Sports Utility Vehicle (SUV) \\ Off-road vehicle}

A $4 \times 4$ vehicle is one that has (usually permanent) four-wheel drive. The majority of saloon cars, hatchbacks and other passenger cars sold in the UK are front-wheel drive only. Some are rear-wheel drive (BMW models for example). Four-wheel drive vehicles are not necessarily endowed with specific off-road capability by design, and some vehicle manufacturers have introduced four-wheel drive versions of models that are more commonly found as front-wheel drive: Audi for example has for many years made available four-wheel drive variants of their A3, A4, A6 and A8 or antecedent models, sold with the Quattro designation. Subaru specialise in four -wheel drive models, only one of which could be described as being near the same market segment as the Land Rover Discovery or Range Rover. Sometimes the term 'all-wheel drive' is used. Generally speaking, the Land Rover models in question can be considered as large $4 \times 4 \mathrm{~s}$, whereas the Land Rover Freelander model is an example of a medium $4 \times 4$.

A Sports Utility Vehicle is a description 'imported' from the US market. The term does not describe a sports car at all, but rather conveys the idea that the vehicles in question have a range of capabilities that cross between work (utility) and leisure (sport). This is a somewhat confusing term because while the SUV segment does indeed capture the Land Rover Discovery and Range Rover, it is also used to embrace a wide range of vehicles that are distinctly 
different in terms of engineering, design and functional capability. It is worth noting, however, that the Land Rover models are classed as light trucks in the US market.

The term 'off-road vehicle' is used to describe a vehicle that has, to some degree, the capability to be used off road. It does not mean that the vehicles are confined to off-road applications in the way that, for example, some very heavy-duty quarry lorries are so confined. The extent to which vehicles are able to go off-road is not precisely defined, and again a wide variety of vehicles may fall into this category. For example, quad-bikes are light-weight, single-seat off-road vehicles used both in work and leisure applications. As discussed below, designing a vehicle to be capable of off-road performance carries a significant efficiency and safety penalty when it is used on normal roads.

\section{The safety issues}

Deaths and injuries from road traffic accidents are a serious issue for public health with multiple causal factors and multiple agencies. One important factor is vehicle design and hence one important agency is the vehicle manufacturers that design and manufacture those vehicles. The safety issue may be divided into those matters concerning impacts between vehicles, and those concerning impacts with pedestrians.

While much has been made of the relatively good safety record in the UK, and while the vehicle manufacturers should get due recognition for the introduction of technologies and features to improve safety in the event of an accident, recent research has shown that a significant proportion of the improvement is attributable to better rescue and recovery systems operated by the emergency services.

In 2003, according to data from the UK Department for Transport, there were 3,508 people killed in road traffic accidents in the UK, 33,707 serious injuries, and 253,392 slight injuries. Of these there were 114 pedal cyclists killed, and 774 pedestrians killed with 7,159 seriously injured. That is, $22 \%$ of deaths from road traffic accidents were pedestrians in 2003. In 2004 there were 3,221 deaths, of which 671 were pedestrians.

In order to gain Type Approval for sale in the European Union all models must meet specified safety standards. These standards, however, pertain to the safety of the occupants. On the $1^{\text {st }}$ October 2005 the first EU pedestrian impact safety standards were introduced for all new models entering the market from that date. Standards such as these can be seen as minimum entry requirements.

Evidence from the US can be a useful starting point to understanding the relative safety performance of large $4 \times 4$ vehicles. In particular, the US data gives an insight into the consequences that arise when a large $4 \times 4$ is in collision with a car. 
It is accurate to say that the US light truck segment upon which this data is based reflects a situation somewhat different to the UK - notably the $4 \times 4$ s are heavier and occupants are less likely to wear seatbelts. On the other hand, these factors may be offset:

- US cars are also larger and heavier on average. There is of course a 'sub-compact' segment of the market, but no representation of European 'super-mini' cars (e.g. Peugeot 206) or city cars (e.g. Smart ForTwo).

- US legal road speed limits are often lower than those in Europe or the UK, particularly in urban areas.

- US legal requirements at junctions are also different, for example with the 'four-way stop' at crossroad junctions in urban areas.

- US driving styles tend to be more relaxed and slower, aided by the almost ubiquitous use of automatic transmission and power steering.

With respect to impacts with other vehicles, the main issues are the relative weight of the $4 \times 4$ / SUV and the incompatibility of these vehicles with the impact structures found on cars. The greater weight means that for a given speed there is more energy to transfer to the other vehicle. The greater height of the $4 \times 4$ means that the point of impact tends to be higher than the bumpers or side-impact beams of the car, thereby allowing greater intrusion into the car or even riding up over the car. The stiffness of the SUV chassis means that it does not absorb the impact energy through progressive deformation, which is the way in which cars manage impacts via 'crumple zones', rather the chassis becomes the means by which energy is transferred to the other vehicle.

With these considerations in mind, the available US data clearly support the view that $4 \times 4$ / SUV vehicles are more dangerous to other road users tha $n$ traditional cars in the event of an accident.

With respect to deaths and injuries caused to pedestrians, the implications for $4 \times 4$ vehicles are somewhat different. In the case of a normal front-engine car of typical height the point of impact with the pedestrian is the bumper, which usually hits on the legs between the knee and the thigh. This primary impact then causes the pedestrian to rotate over the front of the car and results in secondary impacts, with the bonnet, windscreen frame or windscreen, to the head and upper body. The secondary impacts are more likely to result in death or serious injury. Further injury may be caused upon impact with the ground or other objects. Vehicle design improvements to reduce death and serious injury have concentrated removing prominent features on the front of the car that could cause damage, and on managing the energy of the secondary impact. Such features can mitigate the effect of the impact on the pedestrian. Other concepts, such as external airbags, have been explored but not so far used.

With a typical $4 \times 4$ vehicle the front of the vehicle is higher off the ground, and presents a 'wall' of steel, plastic and glass to the pedestrian. This has two consequences. First, the point of impact is higher, and more likely to be in the much more vulnerable torso region of the pedestrian. Second, the pedestrian 
cannot rotate over and onto the bonnet so there is a reduced opportunity to manage the impact forces.

From US data, pedestrians were two to three times more likely to die when struck by a light truck or van compared with a passenger car and that for a given impact speed the likelihood of serious head and thoracic injury is 'substantially' greater.

\section{The environmental issues}

A key target for the European automotive industry is that of an average of 140 $\mathrm{g} / \mathrm{km} \mathrm{CO} 2$ emissions, the figure agreed to be reached between the European automotive industry representative body (ACEA) and the European

Commission by 2008. In 1997, according to the SMMT the average figure for new cars sold in the UK was $189.8 \mathrm{~g} / \mathrm{km} \mathrm{CO} 2$ emissions, falling to $172.1 \mathrm{~g} / \mathrm{km}$ by 2003.

In 2003 the segment $\mathrm{CO} 2$ emissions performance was as shown in the table below.

Segment average and lowest $\mathrm{CO} 2$ emitting models in each segment in the UK, 2003.

\begin{tabular}{|c|c|c|c|c|}
\hline Segment & Model & Fuel & $\mathrm{CO} 2 \mathrm{~g} / \mathrm{km}$ & $\begin{array}{l}\text { Segment } \\
\text { average } \mathrm{CO} 2 \\
\mathrm{~g} / \mathrm{km}\end{array}$ \\
\hline Mini & Smart & Petrol & 113 & 138 \\
\hline Supermini & Citroen C2 & Diesel & 108 & 147 \\
\hline $\begin{array}{l}\text { Lower } \\
\text { Medium }\end{array}$ & Toyota Prius & $\begin{array}{l}\text { Petrol / } \\
\text { Electric }\end{array}$ & 104 & 166 \\
\hline $\begin{array}{l}\text { Upper } \\
\text { Medium }\end{array}$ & $\begin{array}{l}\text { Skoda } \\
\text { Octavia }\end{array}$ & Diesel & 138 & 181 \\
\hline Executive & Audi A6 & Diesel & 154 & 211 \\
\hline Luxury & $\begin{array}{l}\text { Mercedes } \\
\text { S320 }\end{array}$ & Diesel & 204 & 272 \\
\hline Sports & Honda Insight & $\begin{array}{l}\text { Petrol / } \\
\text { Electric }\end{array}$ & 80 & 222 \\
\hline $4 \times 4$ & RAV4 & Petrol & 175 & 244 \\
\hline MPV & $\begin{array}{l}\text { Peugeot } \\
\text { Partner }\end{array}$ & Diesel & 152 & 195 \\
\hline
\end{tabular}

(Source: SMMT) 
The performance of the Land Rover Discovery and Range Rover models is worse than the segment average. The basic data are shown below.

The CO2 emissions performance of the Land Rover Discovery and Range Rover models

\begin{tabular}{|l|l|l|l|}
\hline Model & Variant & Engine & $\begin{array}{l}\text { CO2 emissions } \\
\mathrm{g} / \mathrm{km}\end{array}$ \\
\hline & & & \\
\hline Discovery & V8 S & Petrol & 354 \\
\hline & V8 SE & Petrol & 354 \\
\hline & V8 HSE & Petrol & 354 \\
\hline & TDV6 5st & Diesel & 249 \\
\hline & TDV6 7st & Diesel & 249 \\
\hline & TDV6 S & Diesel & 249 \\
\hline & TDV6 SE & Diesel & 249 \\
\hline & TDV6 HSE & Diesel & 275 \\
\hline Range Rover & 4.2 V8 Super & Petrol & 376 \\
\hline & 4.4 V8 SE & Petrol & 352 \\
\hline & 4.4 V8 HSE & Petrol & 352 \\
\hline & 4.4 V8 Vogue & Petrol & 352 \\
\hline & 4.4 V8 Vogue SE & Petrol & 352 \\
\hline & TD6 SE & Diesel & 299 \\
\hline & TD6 HSE & Diesel & 299 \\
\hline & TD6 Vogue & Diesel & 299 \\
\hline & TD6 Vogue SE & Diesel & 299 \\
\hline & & &
\end{tabular}

(Source: What Car)

\section{A question of responsibility}

However, it is worth considering what Land Rover might have done in a technical sense, as a socially responsible company, to mitigate the situation by improving fuel economy. There are several technical options available. These include:

- Weight reduction

- Alternative fuels

- Cylinder design engineering-activation

- Part-time $4 \times 4$

- Mild hybrid and stop / start cut out systems

- Full hybrid 
The fuel economy measures outlined below would not contribute to an improvement in the safety performance of the vehicles.

Weight reduction offers some scope to improve fuel economy, but in the case of the Land Rover Discovery and Range Rover models the scope for such reduction is limited by the technical choices made and by the simple reality of being large $4 \times 4$ vehicles. The models do employ aluminium in the body structure, but are still heavy vehicles by any standard. The maximum kerb weights are: for the TDV6 manual $2,708 \mathrm{~kg}$; the TDV6 automatic 2,718 kg; and the V8 petrol, 2,704 kg. Many aspects of poor fuel economy derive from the design and market positioning of the vehicles and are the inevitable consequence of trying to match off-road performance with the levels of comfort and convenience expected by those that are in reality going to drive the vehicles in urban areas.

A different design strategy, for example with an aluminium frame and plastic composite body panels, could yield significant weight reduction that would in turn allow a weight reduction spiral as other components and systems could also be reduced in weight.

Alternative fuel vehicles offer some improvements in overall emissions performance according to the UK Vehicle Certification Agency.

Cylinder deactivation systems were first deployed in a 1981 Cadillac, but were withdrawn due to technical and reliability problems. With the advent of modern electronic control and engine management, the concept has been revitalised. In the US, the cylinder deactivation technology concept has been applied to the largest of the 'light truck' vehicles produced by Chrysler and by GM. In the latest generation Dodge Ram 1500 pick-up truck, for example, has this technology, as does the Jeep Grand Cherokee (a large 4x4 similar to the Land Rover Discovery and Range Rover). Chrysler claim that by switching the V8 to a V4 configuration fuel savings of up to $20 \%$ are possible. Honda developed a 3.0 litre V6 with what the company termed 'Variable Cylinder Management' that is claimed to reduce pumping losses by up to $65 \%$. Honda made a more modest claim for $5 \%$ improvement in fuel economy. Vehicles with this technology were launched in the US market and in Japan in 2003.

Mild hybrids and stop-start cut out systems use electric assistance to accelerate a vehicle from rest. In the US, GM has been active in developing this technology that, in their application, is known as a Belt Alternator System. The first application will be an SUV, the Saturn VUE Green Line, to appear for the 2007 model year. Combined with regenerative braking and a modified four-speed automatic transmission it is expected that the BAS will deliver a $12-15 \%$ improvement in fuel economy over the basic model.

Part-time $4 \times 4$ is used to switch off the front-wheel drive element of a fourwheel drive vehicle when all round traction is not required, by disengaging the front-wheel drive shaft. The approach is used in the 2006 Dodge Ram pick-up truck for example. The fuel economy benefit, and hence $\mathrm{CO} 2$ emissions benefit, depends upon the degree to which $4 \times 4$ drive is switched off. $A$ 
reasonable estimate of the difference between a $4 \times 4$ version of a model and a two-wheel drive version is for $5-10 \%$ lower $\mathrm{CO} 2$ emissions from the two-wheel drive version.

Hybrid cars have entered the market in recent years, notably through the efforts by Honda and Toyota. Again, there is a significant benefit in terms of fuel economy. In example is the Lexus RX400h: a large vehicle that weighs up to $2024 \mathrm{~kg}$ and has a CO2 performance of $192 \mathrm{~g} / \mathrm{km}$. This performance illustrates two points. First, that compared with the Land Rover Discovery and Range Rover models, it is possible to achieve between $23 \%$ and $49 \%$ lower $\mathrm{CO} 2$ emissions. Second, that even with this technology, the fuel economy figure is still poor - nearly twice that achieved in the Toyota Prius that employs similar technology.

In a major US study for example it was estimated that a moderate package of measures to include weight reduction, streamlining, low rolling resistance tyres and an integrated starter generator system could yield an improvement of $70 \%$ in fuel economy for a typical SUV (actually a Ford Explorer petrol engine V6) for a cost increase of just 4-7\%. A more aggressive approach with an 'advanced' SUV design including direct injection petrol engines could yield even greater improvements in fuel economy, with a price rise of about $10 \%$.

\section{Conclusions}

It is evident from the Land Rover corporate website, and from the promotional literature, that the go-anywhere promise of the models is the primary claim to distinction. Photographs of the models portray almost universally scenes bereft of other human features, with vehicles positioned within actual or stylised remote terrains. This is important because the emotional value of brands is often as crucial as the tangible content. In this respect, brands represent life-style statements for consumers, they are public statements for consumers wishing to establish to the wider social world their values and status.

In effect, the idea of the 'freedom of the open road' so often promised in mainstream car advertising has been replaced, a frank acknowledgement that our roads today are so congested that such a freedom is utterly unrealisable. In stead, these images offer the prospect of the 'freedom of the open countryside'.

In reality, Land Rover must know that many of these vehicles will not be used anywhere other than city environments, despite the host of inappropriate features that render these vehicles more dangerous and more resourceintensive than need be the case. Perhaps issues of 'responsibility' are not always distinct and clear, but what Land Rover and other companies need to realise is that the judgements are not made in a court of law, but in social discourse. 